\title{
ASSESSMENT OF HEALTH HAZARDS ASSOCIATED WITH AGROCHEMICALS USAGE AMONG VEGETABLE FARMERS IN MAIDUGURI AND ITS ENVIRONS, NIGERIA
}

\author{
Bolori, M.T. ${ }^{1}$, Mustapha, S. B. ${ }^{* 2}$ and Jidda, B. ${ }^{3}$ \\ ${ }^{1}$ Department of Community Medicine, University of Maiduguri, Nigeria \\ ${ }^{2}$ Department of Agricultural Extension Services, University of Maiduguri, Nigeria \\ ${ }^{3}$ Department of Crop Protection, University of Maiduguri, Nigeria \\ *Email: sbmustapha@unimaid.edu.ng \\ Mobile Phone: +234(0) 7060573884
}

\begin{abstract}
The study assessed health hazards associated with agrochemicals usage among vegetable farmers in Maiduguri and its Environs, Nigeria. Multi - stage sampling techniques was employed to select 160 vegetable farmers for this study. Both descriptive (frequency distribution and percentages) and inferential (logit regression) statistics were used to analyze the data. The study revealed that majority (59.37\%) of the respondents were members of vegetable farmers' organization and half (50.00\%) of them were visited by extension agents less than thrice with majority (85.00\%) of them had no access to credit during the period under study. The study revealed the most common symptoms of health hazards associated with agro-chemicals usage among respondents were skin problems (67.70\%), dizziness (57.50\%) and headache (52.50) in the study area. The logit regression revealed that extension contact had a positively significant influence at $p<0.05$ level, while access to credit, sources of credit, availability of agrochemicals shop and membership of FBOs had significant influence at $p<0.10$ level each on wearing of PPEs during agro-chemicals application. The most important constraint affecting PPEs use was high cost of PPEs as reported by $55.00 \%$ of the respondents. The study recommended that vegetable farmers in the study area should be encouraged to form strong farmer organisations that will enable them to work as a team in order to eradicate or minimize the constraints of high cost of PPEs by obtaining subsidized PPEs from government for improved use of the same.
\end{abstract}

Key Words: Agrochemicals, Assessment, health hazards, usage, Vegetable farmers 


\section{INTRODUCTION}

Vegetable production is one of labor intensive production activities, and is a place of work where farmers are exposed to different safety hazards. As a result of this, farmers lose direct and indirect costs related to vegetable farming illnesses (Afshari et al., 2019). The direct costs for vegetable farmers include pain and suffering from the injury or illness, loss of income, loss of health-care costs, and while the indirect costs include time lost by family members to care for the disabled worker and utmost economic shock and social chaos (Saeed et al., 2017).

Agro-chemicals as agricultural inputs are composed of active ingredients and inert materials, which are used in their formulation to control pests and diseases to increase productivity. Wang et al. (2017) noted that most of the agro-chemicals are dangerous, toxic and can cause serious health hazards to human being and the environment. That was why; Adeogun and Agbongiarhuoyi (2009) recommended some precautionary measures in the application of agrochemicals either as sprays or dust, viz: wearing of nose shield to avoid inhalation; putting on protective clothing; rubber gloves and boots; refraining from smoking, eating and drinking; covering food and water to avoid contamination. Also during application, agro-chemicals must not be spilled or sprayed on skin. The post-application safety measures include washing of hands and face and changing to clean clothes after spraying. Also, contaminated clothing must be washed thoroughly; chemicals must be stored in the original container and kept out of the reach of children. These precautionary measures are usually contained on the agro-chemicals container or label for the users or the farmers to note, and most unfortunately, majority of Nigerian farmers are illiterates (Adeogun and Agbongiarhuoyi, 2009; Ojo et al., 2016). They added that most of the farmers would have been engaging in some operational habits that may make them vulnerable to some health hazards associated with the agro-chemicals usage.

Agro-chemicals are considered an essential part of modern agriculture, playing a key role in vegetable production to control harmful insects, weeds, and pathogenic organisms (Jallow et al., 2017). The unprotected use of agro-chemicals can cause severe threats to human health and the environment, making it a very important public health concern (Saeed et al., 2017). Concerns about adverse health effects of agro-chemicals, particularly in the developing nations, have been decreased by adopting protective behaviors (PBs) and personal protective equipments (PPEs) (Khan and Damalas, 2015). The Food and Agriculture Organization (FAO), the World Health Organization (WHO), and various non-government organizations focusing on low and middleincome countries have emphasized improving PBs and PPEs for farmers in agro-chemicals use (Afshari et al., 2019). Studies indicated that PPEs and behaviors are effective in reducing farmers' exposure to agro-chemicals (Balkhyour et al., 2019), adding that despite indications of efficacy, it has been shown that protective measures are not frequently used. And using PPEs and engaging in safe behaviors depend on a variety of factors such as farmers' knowledge of agrochemicals hazards and correct use of practices, farmers' beliefs and perceptions about the risks of pesticides exposure, perceived and actual barriers for the adoption of safety behaviors and use of PPEs by farmers and social influences (Tadesse et al., 2016); Wang et al., 2017). Adding, that identifying the various effective factors in using protective measures during agro-chemicals exposure by vegetable farmers is necessary to provide insight into the underlying motives which 
drive farmers' safe agro-chemicals behaviors. Having a specific framework could improve the understanding of farmers' behavior within the context of the agricultural system where they work (Balkhyour et al., 2019).

Use of personal protective equipment (PPE) is one of important measures to safeguard workers from exposure to occupational hazards, especially in developing countries where conventional occupational safety control principles remain a challenge to implement (Khan and Damalas, 2015).Workers use of PPE is affected by socio-demographic, behavioral and work environment factors (Wang et al., 2017). In vegetable production, farmers use different protective devices at different production sessions. For example, they need to wear respirator, gloves, goggle, and rain boots, overall, ear plugs and mask at spinning work.

Policies or measures for delivering health and safety services to vegetable farmers are limited in Borno State, Nigeria. This not only limits their access to information and training opportunities, but also places the vegetable farmers at a greater risk to occupational injuries and diseases. Furthermore, literature showed that vegetable farmers lack the knowledge on proper use of protective measures and are least aware of health effects emanating from the activities and materials in their work environments. There is also a dearth of studies describing PPE utilization among vegetable farmers in the study area. This study presented the findings of a study which investigated PPE utilization and associated factors among vegetable farmers in Maiduguri and its environs, Borno State, Nigeria. This study addresses a critical gap in understanding PPEs utilization in Maiduguri and its environs, Borno State, Nigeria and contributes to the growing workplace safety research in Nigeria. Such studies may also help in developing evidence-based intervention strategies targeted at promoting vegetable farmers safety and health. Against this background, this study examined extension support to reduction of health hazards associated with agro-chemicals usage by vegetable farmers in the study area. The specific objectives of the study were to: -

(i) identify the institutional characteristics of vegetable farmers in the study area;

(ii) ascertain the health hazards associated with agro-chemicals usage among the respondents;

(iii) assess the current usage of personal protective equipments (PPEs) among the respondents;

(iv) determine the influence of institutional-factors on personal protective equipments (PPEs) usage among respondents; and

(v) investigate the constraints to improved use of PPEs among the respondents.

\section{METHODOLOGY}

The study was conducted in Maiduguri and its environs, Borno State, Nigeria, which is located in the extreme north-east corner of Nigeria. The Maiduguri Metropolis is made up with some parts of Jere, Konduga and Mafa Local Government Areas. Maiduguri Metropolis has a population density of 1,738 people per square kilometer, which lies between latitudes $11^{\circ} .83^{\prime}$ North of the equator and longitudes 130.501 East of the Greenwich Meridian (Daura, 2001). The hottest period is between March and May with $44.4^{\circ} \mathrm{C}$, while, the coldest Month is January, with $12.6^{\circ} \mathrm{C}$ 
(Nigerian Meteorological Agency (BOSADP, 2003). Agriculture is the main stay of the economy of Maiduguri and its environs, Borno State and vegetables (onion, pepper, tomatoes etc) are one of the major crops produced in the area.

Primary data was generated from vegetable farmers through the use of structured and pre- tested interview schedules. Interview schedules were employed as a result of the assumed low level literacy of the respondents. These were administered by enumerators who were trained for this purpose under the supervision of the researcher. In some instances, discussions with key informants and experts were held. Secondary information from Area Extension Officers (AEOs) of BOSADP was used to complement the primary data. Other sources of secondary information include research reports, government publications, textbooks, journal publications and other write-up that are relevant to this study.

Multi - stage sampling techniques was employed to select the respondents for this study. The first stage of the sampling was purposive selection of four (4) wards based on the predominance of vegetable farming. At the second stage, three (2) vegetable associations were selected at random from each of the wards to be sampled. A simple random sample gives each household in the area under study an equal chance of being selected, and study findings could be fairly generalised across the study population. At the third stage, 20 respondents were proportionately selected from each of the selected vegetable associations. Therefore, 160 respondents were used for the study. The lists of the communities and vegetable farmers were obtained from BOSADP for this research project.

Descriptive and inferential (logit regression) statistics were used to analyze the data collected for this study. These were used to achieve the specific objectives of the study. Descriptive statistics such as frequencies and percentages were used to achieve objectives (i), (ii), (iii) and (v). The logit regression analysis was used to determine the institutional factors influencing agrochemical usage in vegetable production among the respondents (specific objective iv). The regression model in its explicit form is given is theoretically expressed as:

$\mu=B_{0}+B_{1} X_{1}+B_{2} X_{2}+\ldots \ldots \ldots B_{n} X_{n}+e$

Where:

$\mu=$ Likelihood of Usage of PPEs, otherwise labeled as Utilised PPEs. It is quantified as any vegetable farmer that used at least $50 \%$ of the identified PPEs in this study; and did not Used PPEs as any vegetable farmer that used less than $50 \%$ of the identified PPEs in this study.

$\mathrm{B}_{0}=$ intercept;

$\mathrm{B}_{1} \ldots \ldots . \mathrm{n}=$ estimated parameters;

$\mathrm{X}_{1} \ldots \ldots . \mathrm{n}=$ Set of independent variables; 
For the Logit Model, the equation for the relationship between institutional characteristics of respondents and the likelihood of their usage of PPEs is specified as:

Utilized PPEs $=\mathrm{B}_{0}+\mathrm{B}_{1} \mathrm{X}_{1}+\mathrm{B}_{2} \mathrm{X}_{2}+\mathrm{B}_{3} \mathrm{X}_{3}+\mathrm{B}_{4} \mathrm{X}_{4}+\mathrm{B}_{5} \mathrm{X}_{5}+e$

Where:

Utilized PPEs = likelihood of usage of PPEs, Dummy variable (1 for usage and 0 for non-usage)

$\mathrm{Y}_{\mathrm{i}}=$ Respondents likelihood of usage of PPEs

$\mathrm{X}_{1}=$ access to credit;

$\mathrm{X}_{2}=$ sources of credit;

$\mathrm{X}_{3}=$ extension contact;

$\mathrm{X}_{4}=$ availability of agro-chemicals shop;

$\mathrm{X}_{5}=$ membership of Farmer Based Organizations (FBOs);

$\mathrm{e}=$ Error term which satisfies all the econometric conditions of Ordinary Least Square (OLS) estimates.

\section{RESULTS AND DISCUSSION}

\section{Institutional Characteristics of Respondents}

The institutional characteristics of the respondents are presented in Table 1. The studies revealed that majority $(59.37 \%)$ of the respondents were members of vegetable farmers' organization, while $40.63 \%$ of them were non-members. This implies that the respondents might be aware of the health hazards associated with the use of agro-chemicals and their tendency to use PPEs could be high. Membership of farmers' organization has bearing on the capacity of vegetable farmers to use PPEs in the study area. For instance, farmers' cooperative society link members to sources of inputs and technologies, educate their members on how to utilize such inputs/technologies as well as link them to markets where they can dispose of their produce. These could positively influence utilization of PPEs among members of the organizations. 
Table 1: Distribution of respondents by institutional characteristics $(n=160)$

\begin{tabular}{|l|l|l|}
\hline Institutional characteristics & Frequency (No.) & Percentage (\%) \\
\hline Membership of vegetable farmer organization & 95 & 59.37 \\
\hline Member & 65 & 40.63 \\
\hline Non-member & 80 & 50.00 \\
\hline Extension contact per season & 55 & 35.00 \\
\hline Less than 3 & 24 & 15.00 \\
\hline $3-6$ & 24 & 15.00 \\
\hline 7 and above & 136 & 85.00 \\
\hline Access to credit & 17 & 10.63 \\
\hline Have access & \multicolumn{2}{l}{} \\
\hline No access & 80 & 50.00 \\
\hline Source of Agro-chemicals \& PPEs & 22 & 13.75 \\
\hline $\begin{array}{l}\text { Borno State Agricultural Development } \\
\text { Programme }\end{array}$ & 40 & 25.00 \\
\hline Farmer organizations & \multicolumn{2}{l}{} \\
\hline Agro-chemical retailers &
\end{tabular}

\section{Source: Field survey; 2018}

Table 1 indicated that most $(50.00 \%)$ of the respondents were visited by extension agents less than thrice during the period under study. About $35.00 \%$ of them received $3-6$ visits, while only $15.00 \%$ received more than seven visits in the production season under study. This is a clear indication that the respondents received few visits from extension agents in the study area. The implication could be that, this would have adverse effects on respondent's level of utilization of PPEs in the study area. Extension visits among small - scale farmers in developing countries is generally low as attested by empirical evidence (Afshari et al., 2019). Frequency of extension visits is expected to give room for information exchange between the vegetable farmers and the extension agents. However, effective extension services face severe setbacks in many developing countries occasioned by public service dominated extension, characterized by lack of staff incentives, weak political commitment and staff not being abreast to emerging technological developments (Jallow et al., 2017).

Table 1 showed the access to credit among respondents. The result revealed that majority $(85.00 \%)$ of the respondents had no access to credit, while only $15.00 \%$ of them had access to credit in the study area during the study period. The possible reason for the low proportion of respondents accessing credit could be the difficult procedures involved in formal institutions, coupled with high interest rates associated with informal lending institutions. However, cash is needed to purchase PEEs as well as the complementary inputs where necessary. This explains 
why access to credit is often observed as an important determinant of utilization of agricultural technologies including the PPEs.

Distribution of respondents in Table 1 indicated that most $(50.00 \%)$ of the respondents had farmer organization as their major source of agro-chemicals and PPEs, $25.00 \%$ of them had fellow farmers, and $13.75 \%$ had Agro-chemical retailers, while only $10.63 \%$ of them had BOSADP. The agro-chemicals, PPEs and their sources play important role in increasing productivity of vegetable farmers in the study area. Vegetable farmers, who were aware of such important information, could prefer getting agro-chemicals and PPEs from reliable sources. The source of agro-chemicals and PPEs as well as the credibility of such sources has bearing on the utilization of agro-chemicals and PPEs in the study area. Farmers who got their agro-chemicals and PPEs directly from extension agents/organizations were likely to get improved utilization of agro-chemicals and PPEs from extension agents that could perform optimally, due to its authenticity. This can form an incentive for improved utilization of agro-chemicals and PPEs in the study area.

\section{Health Hazards Associated With Agro-Chemicals Usage among Respondents}

Table 2 showed the health hazards associated with agro-chemicals usage among respondents in the study area. The study revealed the most common symptoms that were reported by the respondents. Among the symptoms reported, skin problems (67.70\%), dizziness (57.50\%) and headache (52.50) as the most common system among the respondents, while, cough was being reported as the least common symptom (20.60\%) in the study area. It is universally acknowledged that the primary route of exposure to pesticides is via the skin, because agrochemical products can splash or spill into exposed skin during pouring and mixing of concentrated agro-chemical formulations and spraying when dust can contaminate exposed skin or clothing (MacFarlane et al., 2008). Therefore wearing of protective clothes is the most important safety measure aimed to avert or minimize skin contamination as far as possible and, if this occurs, to ensure efficient decontamination.

Table 2: Health Hazards Associated with Agro-chemicals Usage among Respondents

\begin{tabular}{|l|c|l|}
\hline Symptom & Frequency (No.) & Percentage (\%) \\
\hline Skin problems & 108 & 67.70 \\
\hline Dizziness & 92 & 57.50 \\
\hline Headache & 84 & 52.50 \\
\hline Excessive sweating & 80 & 50.00 \\
\hline Sneezing & 48 & 30.00 \\
\hline Poor vision & 35 & 21.85 \\
\hline Cough & 33 & 20.60 \\
\hline
\end{tabular}

Source; field survey, 2018

Multiple responses exists 


\section{Current Usage of Personal Protective Equipments (PPEs)}

The study revealed that majority $(67.00 \%)$ of the respondents were caps/hats in the study area (Table 3) and about $56.00 \%$ of the respondents wear garments covering most parts of the body. In order to prevent the inhalation of chemical particles, it is recommended to wear a mask covering nose and mouth, which was why majority $(63.00 \%)$ of the respondents had to wear mask.

Table 3: Current Usage of Protection Clothes among Respondents

\begin{tabular}{|l|l|l|}
\hline Use of Protective Cloths & Frequency (No.) & Percentage (\%) \\
\hline Wearing of protective garments & 66 & 56.00 \\
\hline Wellington boots & 08 & 11.00 \\
\hline Masks & 74 & 63.00 \\
\hline Rubber Gloves & 43 & 36.00 \\
\hline Goggles & 04 & 03.00 \\
\hline Caps/hats & 79 & 67.00 \\
\hline
\end{tabular}

Source; field survey, 2018

Multiple responses exists

Number of vegetable farmers using protective gloves is as low as $36.00 \%$ during agro-chemicals formulation, pouring, mixing, loading and spraying. Only 11 percent of respondents wear boots at the time of agro-chemicals application. The reason for not wearing boots might be the difficulty of wearing the boots in muddy soils. However, not wearing of boots has a high possibility of pesticide exposure in vegetable cultivation. None wearing of boots is more critical in fields with stagnant water such as rice fields where pesticides contaminate water resulting in high possibility of dermal exposure. Wearing a protective cover for eye is important especially when applying pesticides for crops like beans, but very few (3.00\%) wear goggles (eye cover) while spraying the agro-chemicals.

\section{Factors influencing famers' decision to wear personal protective equipment (PPE)}

Table 4 presents the result of logit regression that estimated the factors influencing farmers' decision to put on PPEs when applying agro-chemicals. The study indicated that access to credit; sources of credit, extension contact, availability of agro-chemicals shop and membership of Farmer Based Organizations (FBOs) had a significant influence on vegetable farmers' decision to put on PPEs. 
Table 4 Logit results on Institutional factors influencing Respondents' decision to put on PPEs

\begin{tabular}{|l|l|l|l|l|l|l|}
\hline Variables & Coef. & $\begin{array}{l}\text { Std. } \\
\text { Err. }\end{array}$ & Z & $\begin{array}{l}\text { P- } \\
\text { values }\end{array}$ & \multicolumn{2}{|l|}{$\begin{array}{l}\text { 95 \% conf. } \\
\text { interval }\end{array}$} \\
\hline Constant & $6.684^{* *}$ & 2.315 & 2.89 & 0.004 & 2.147 & 11.221 \\
\hline Access to credit & $0.306^{*}$ & 0.128 & 2.39 & 0.017 & 0.556 & 0.055 \\
\hline Sources of credit & $0.192^{*}$ & 0.078 & 2.45 & 0.014 & 0.345 & 0.038 \\
\hline Extension contact & $2.721^{* *}$ & 1.039 & 2.62 & 0.009 & 0.684 & 4.757 \\
\hline $\begin{array}{l}\text { Availability of agro-chemicals } \\
\text { shop }\end{array}$ & $4.468^{*}$ & 2.119 & 2.11 & 0.035 & 0.314 & 8.622 \\
\hline Membership of FBOs & $0.031^{*}$ & 0.995 & 0.03 & 0.025 & 1.981 & 1.919 \\
\hline
\end{tabular}

Source; field survey, 2018

Log likelihood $=-43.463$

Pseudo $\mathrm{R}^{2}=0.683$

$\operatorname{LRchi}^{2}(9)=187.30$

Pro $>$ chi $^{2}=0.0000$

$*$ and $* *=10 \%$ and $5 \%$ significance level respectively

Access to credit had a positively significant influence $(p<0.10)$ on wearing of PPEs during agro-chemicals application. This suggests that with access to credit, vegetable farmers had an increased purchasing power to buy PPEs and use during agro-chemicals application. Sources of credit had a positively significant influence $(p<0.10)$ on wearing of PPEs during agro-chemicals application. This suggests that with increased sources of credit, vegetable farmers access to credit increases to purchase PPEs during agro-chemicals application. Extension contact had a positively significant influence $(p<0.05)$ on wearing of PPEs during agro-chemicals application. This suggests that with extension services, vegetable farmers are educated on the importance of wearing PPEs during agro-chemicals application. Availability of agro-chemicals shop had significant influence $(p<0.10)$ on wearing of PPE when applying agro-chemicals. This empirical result implies that the probability of wearing PPE increases with agro-chemicals shop availability. This might be due to education of farmers on the importance of wearing PPEs by shop attendants. Membership of FBOs had significant influence $(p<0.10)$ on wearing of PPEs when applying agro-chemicals. This empirical result implies that the probability of wearing PPEs increases with membership of FBOs in the study area.

\section{Constraints to Improved Use of PPEs among Respondents}

The major constraints to improved use of PPEs are presented in Table 5. The most important constraint affecting PPEs use was high cost of PPEs, as reported by $55.00 \%$ of the respondents, followed by lack of training on the use of PPEs. According to Ogunjimi and Farinde (2012), high cost of PPEs is a major barrier to their use, hence reduced cost of PPEs are needed to better PPEs compliance. The least constraints to improved use of PPEs were inadequacy of PPEs and 
unavailability of PPEs with $08.75 \%$ and $04.37 \%$ respectively. This implies that there were available and as well as adequate number of PPEs for use in the study area.

Table 5: Distribution of major Constraints to Improved Use of PPEs among Respondents

\begin{tabular}{|l|l|l|}
\hline Constraints & Frequency (No.) & Percentage (\%) \\
\hline High cost of PPEs & 88 & 55.00 \\
\hline Inadequacy of PPEs & 14 & 08.75 \\
\hline Lack of training on the use of PPEs & 51 & 31.88 \\
\hline Unavailability of PPEs & 07 & 04.37 \\
\hline
\end{tabular}

Source; Field survey, 2018

\section{CONCLUSION AND RECOMMENDATIONS}

This study has revealed potential opportunities for human and environmental exposure to pesticides in the study area. The findings are important in contributing to advocacy for training and education of vegetable farmers' on the repercussions or health hazards associated with the various operational habits they exhibit during agro-chemicals use. The study concluded that vegetable farmers' PPEs usage pattern is poor among the respondents in the study area. The most important constraint affecting PPEs usage was high cost of PPEs and lack of training on the use of PPEs. Based on the findings of the study, the following recommendations are therefore made:

(i). Vegetable farmers in the study area should be encouraged to form strong farmer organisations that will enable them to work as a team in order to eradicate or minimize the constraints of high cost of PPEs. They should, through the farmer organisations ensure that inputs including agro-chemicals as well as PPEs are obtained through subsidy from government for improved use of the same.

(ii). Access to credit should be improved, since this study indicated that credit could significantly influences the use of PPEs among the respondents in the study area

(iii). Extension agents of ADP and other agencies such as NGOs should take up the challenges of educating/training vegetable farmers on appropriate pattern of agro-chemicals and PPEs usage in the study area.

\section{ACKNOWLEDGEMENT}

The financial support of the Tertiary Education Trust Fund (tetfund) in carrying out this study is gratefully acknowledged. We would also like to thank the vegetable farmers and extension staff in the study areas for their good cooperation during the course of the study, and lastly research assistants for their active participation in data collection for this research study. 


\section{REFERENCES}

Adeogun S. O. and Agbongiarhuoyi A. E. 2009. Assessment of Cocoa Farmers Chemical Usage Pattern in Pest and Disease Management in Ondo State, Nigeria. J. Innov. Dev. Strategy. $3(2): 27-34$.

Afshari, M., Poorolajal, J., Rezapur-Shahkolai, F., Assari, M. J. and Karimi-Shahanjarini, A. (2019). Which Factors Influence Farmers' Use of Protective Measures During Pesticides Exposure? Workplace Health \& Safety, July, page 338-349.

Balkhyour, M. A., Ahmad, I. and Rehan, M. (2019). Assessment of personal protective equipment use and occupational exposures in small industries in Jeddah: Health implications for workers. Saudi Journal of Biological Sciences, 26: 653-659.

Borno State Agricultural Development Programme (BOSADP) (2003). Borno State Agricultural Development Programme (BOSADP) Annual Report, Borno State of Nigeria.

Daura, M. M. (2001). The physical environment and development: A study of Borno region in environment and development issues in Sub - Sahara Africa. Seminar Series, Vol.1. Faculty of Social and Management Sciences, University of Maiduguri, Nigeria, Pp34 47.

Jallow, M. F. A., Awadh, D. G., Albaho, M. S., Devi, V. Y. and Thomas, B. M. (2017). Pesticide knowledge and safety practices among farm workers in Kuwait: Results of a survey. International Journal of Environmental Research and Public Health, 14, Article 340.

Khan, M. and Damalas, C. A. (2015). Factors preventing the adoption of alternatives to chemical pest control among Pakistani cotton farmers. International Journal of Pest Management, 61, 9-16.

MacFarlane, E. A., Chapman, A., Benke, G., Meaklim, J., Sim, M. and McNeil, J. (2008). Training and other predictors of personal protective equipment use in Australian grain farmers using pesticides. BMJ Publishing Group, Volume 65, Issue 2, http://dx.doi.org/10.1136/oem.2007.034843]

Ogunjimi1, S. I. and Farinde, A. J. (2012). Farmers' Knowledge Level of Precautionary Measures in Agro-Chemicals Usage on Cocoa Production in Osun and Edo States, Nigeria. International Journal of Agriculture and Forestry, 2(4): 186-194.

Ojo, T. F., Kolodoye, G. F. and Olaniran, F. I. (2016). Assessment of precautionary measures in agro- chemicals usage among Urban arable crop farmers in Oyo State, Nigeria.

Ethiopian Journal of Environmental Studies \& Management, 9(Suppl. 1): 804 - 814. http://dx.doi.org/10.4314/ejesm.v9i1.1S. 
Saeed, M. F., Shaheen, M., Ahmad, I., Zakir, A., Nadeem, M., Chishti, A. A. and Damalas, C. A. (2017). Pesticide exposure in the local community of Vehari district in Pakistan: An assessment of knowledge and residues in human blood. Science of the Total Environment, $587,137-144$.

Tadesse, S., Kelaye, T. and Assefa, Y. (2016).Utilization of personal protective equipment and associated factors among textile factory workers at Hawassa Town, Southern Ethiopia. Journal of Occupational Medicine and Toxicology, 11:6pp1-7.

Wang, J., Deng, Y. and Ma, Y. (2017). Relationships between safe pesticide practice and perceived benefits and subjective norm, and the moderation role of information acquisition: Evidence from 971 farmers in China. International Journal of Environmental Research and Public Health, 14. 